
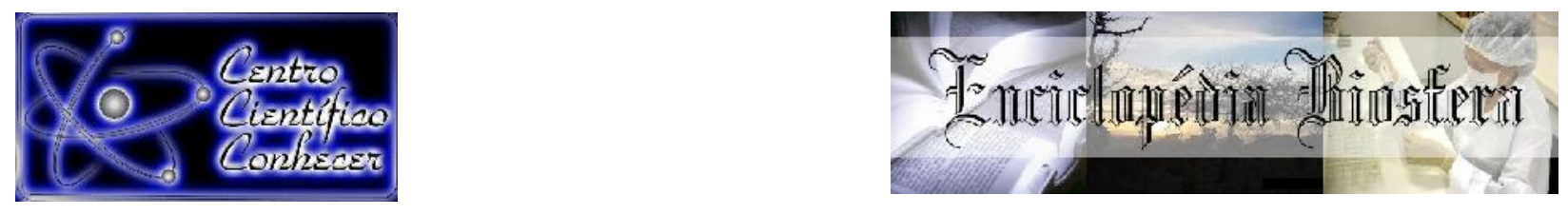

\title{
INCIDÊNCIA DE DENGUE NOS ANOS DE 2016 E 2017 NO BAIRRO SANTA RITA EM GOVERNADOR VALADARES/MG
}

\author{
Vânia Guimarães da Silva ${ }^{1}$, Wanderson Batista dos Santos ${ }^{1}$
}

1 Professores do Instituto Federal de Minas Gerais, campus Governador Valadares

(vania.guimaraes@ifmg.edu.br; wanderson.batista@ifmg.edu.br).

Recebido em: 22/09/2018 - Aprovado em: 23/11/2018 - Publicado em: 03/12/2018

DOI: 10.18677/EnciBio 2018B98

\begin{abstract}
RESUMO
Este artigo analisou a incidência de dengue no bairro Santa Rita, no município de Governador Valadares/MG, no biênio 2016 e 2017. A dengue é uma doença causada por vírus constituído por quatro sorotipos: DENV-1, 2, 3 e 4. A transmissão ocorre por meio da picada da fêmea infectada do mosquito Aedes aegypti, que se encontra totalmente adaptado ao meio urbano e prolifera-se rapidamente. $O$ trabalho foi embasado em pesquisa de análise quantitativa indireta, que compreende análise do total de notificações/investigações dos casos de dengue no referido bairro. Observou-se, no espaço analisado, um aumento significativo da doença no ano de 2017 em relação a 2016, fato que contrasta com os dados apresentados no Brasil no mesmo período. Desse modo, é fundamental que os órgãos de saúde e de vigilância sanitária estejam atentos a tais casos, e, junto à população, dediquem-se à eliminação de focos do vetor, já que essa é a forma mais eficiente de combate à doença.
\end{abstract}

PALAVRAS-CHAVE: Aedes aegypti, dengue, incidência.

\section{INCIDENCE OF DENGUE IN THE YEARS OF 2016 AND 2017 IN THE SANTA RITA DISTRICT IN GOVERNADOR VALADARES / MG}

\begin{abstract}
Dengue fever is a disease caused by a virus composed of four serotypes: DENV-1, 2, 3 and 4. The present study analyzed the incidence of dengue fever in the Santa Rita neighborhood, in the municipality of Governador Valadares/MG, in the 2016 and 2017 biennium. transmission occurs through the bite of infected female Aedes aegypti mosquito, which is fully adapted to the urban environment and proliferates rapidly. The study was based on indirect quantitative analysis, which includes analysis of the total number of reports/investigations of dengue cases in this neighborhood. In the space analyzed, a significant increase of the disease was observed in 2017 compared to 2016, a fact that contrasts with the data presented in Brazil in the same period. In this way, it is essential that the health and health surveillance agencies are attentive to such cases and, together with the population, focus on the elimination of outbreaks of the vector, since this is the most efficient way to combat the disease.
\end{abstract}

KEYWORDS: Aedes aegypti, dengue, incidence. 


\section{INTRODUÇÃO}

A dengue é uma doença viral pertencente ao grupo das arboviroses, e transmitida ao ser humano pelo diptero Aedes aegypti. De acordo com a sua classificação biológica, o vírus pertencente ao gênero Flavivirus, família Flaviviridae possui quatro sorotipos: DENV-1, DENV-2, DENV-3, DENV-4, os quais podem causar tanto a dengue clássica (DC) como a febre hemorrágica da dengue (FHD) (LOPES et al., 2014). A transmissão ao humano se dá quando a fêmea do mosquito alimenta-se de sangue contaminado. A partir daí, o vírus passa por um período de incubação de oito a doze dias, ficando assim o vetor apto a infectar outra pessoa; a doença começa a se manifestar a partir do sexto dia de contaminação (CATÃO, 2012). O indivíduo torna-se imune a cada contato com um sorotipo diferente da doença, podendo assim ser contaminado por até quatro vezes (INSTITUTO OSWALDO CRUZ, 2017).

A dengue clássica apresenta vários sintomas, como febre aguda com duração de até sete dias, acompanhada de cefaleia, prostração, dor retrorbitária, artralgia, exantema e dores articulares. Na dengue hemorrágica, o doente apresenta uma queda do número de plaquetas sanguíneas com valor igual ou inferior a $100.000 / \mathrm{mm}$ cúbicos em algum momento no decorrer da doença, além de tendências hemorrágicas, como sangramento gengival e de mucosas do trato gastrintestinal entre outros. A taxa anual de infecção pelo vírus varia de 50 a 100 milhões, na forma hemorrágica. Nessa fase mais aguda da doença, constata-se uma mortalidade em torno de $5 \%$ (BRASIL, 2014).

Os indivíduos, a sociedade e os sistemas de saúde padecem as consequências do surgimento da dengue. As pessoas que são acometidas pela doença, mesmo em casos mais comuns, isto é, os de menor gravidade, são forçadas a ficar de repouso por vários dias. Em decorrência disso, os custos pessoais, econômicos e sociais dessa doença são altos (FERREIRA et al., 2016).

Variados fatores são favoráveis ao desenvolvimento do mosquito transmissor, destacando-se o clima, o crescimento populacional desordenado, a migração rural- urbana, a inadequação de infraestrutura básica das cidades que relacionam diretamente na transmissão da dengue (COSTA et al. 2008). Embora a distribuição urbana da doença seja limitada pela distribuição do vetor, sua simples presença não é suficiente para tanto. Vários são os parâmetros que interferem no padrão de transmissão da dengue, entre os quais pode-se citar a dinâmica de multiplicação do vírus, a ecologia e o comportamento de seus vetores, além da ecologia, comportamento e imunidade de seus hospedeiros humanos (JANSEN; BEEBE 2010).

De acordo com Camara et al. (2007), a dengue é encontrada nos 27 estados da Federação, sendo responsável por $60 \%$ das notificações nas Américas. Verifica-se que o estado de Minas Gerais foi uma das unidades da Federação que mostrou crescimento mais expressivo da doença nos últimos anos. Os primeiros registros da doença foram relatados em 1987 (PONTES; RUFFINO-NETTO, 1984). Em 2009, Minas Gerais foi apontado como o segundo estado que mais apresentou casos da doença no país, sendo Curvelo, Coronel Fabriciano, Ipatinga, Belo Horizonte e Governador Valadares as cidades que mais se destacaram devido às maiores ocorrências da doença (BRASIL, 2009).

Muitas doenças sofrem influência ou são causadas por fatores ligados ao meio ambiente. Se se conhecer a maneira como eles interferem na saúde, é possível obter um importante meio para o planejamento de programas de prevenção (BONITA, 2010). A disposição correta de resíduos sólidos, por exemplo, está 
diretamente ligada à proliferação de vetores, uma vez que os centros urbanos sofrem com acúmulo de lixo, que propicia o aumento de alagamentos, emissão de poluentes, gerando vários impactos ambientais (JACOBI, 2011). O Poder Público em diversas esferas tem direcionado esforços em campanhas para conscientizar a população a reduzir criadouros do mosquito. Observa-se, no entanto, que os programas de prevenção mostram-se, frequentemente, ineficazes, insuficientes ou ambos (GUZMAN et al., 2012). O fato pode ser atribuído devido ao Aedes aegypti, vetor da dengue, ser capaz de adaptar-se facilmente e conseguir reproduzir-se inclusive em águas poluídas e em elevadas altitudes (RODRIGUES et al., 2016).

Considera-se satisfatório, segundo o Ministério da Saúde, o nível de infestação do Aedes aegypti cujo percentual esteja abaixo de 1\%. Aponta-se até 3,9\% como risco médio. Já acima de $4 \%$ é considerado de alto risco de transmissão das doenças relacionadas ao vetor. Nestes casos, o monitoramento deve ser contínuo: pela verificação de água limpa e parada nos pratos de plantas, da vedação total dos recipientes de armazenando de água e da verificação de ralos e recipientes para alimentação de animais de estimação. É salutar que, ao menos uma vez por semana, haja limpeza de criadouros, a fim de conter a proliferação do vetor, cujo ciclo - do ovo ao mosquito adulto - leva de 7 a 10 dias (INSTITUTO OSWALDO CRUZ, 2017).

A dengue é uma doença de "notificação compulsória semanal", conforme Portaria Ministerial $n^{\circ} 1.271$ de junho de 2014 (BRASIL, 2014). Por isso, todos os casos suspeitos devem ser notificados às autoridades de saúde pública municipal (vigilância epidemiológica e ambiental), para que seja investigada a origem da doença, ou seja, Local Provável de Infecção (LPI) e a existência de outros casos na área de moradia e de trabalho do doente (circulação viral), a fim de verificar a presença de vetores.

Segundo Ministério da Saúde (BRASIL, 2018), os casos de dengue tiveram queda nos anos de 2016 para 2017 no país: em 2016 foram registrados 1.483 .623 casos prováveis de dengue, já em 2017 foram 252.054 casos prováveis da doença. Em Minas Gerais, de acordo com o Boletim Epidemiológico, que apresenta dados do monitoramento da dengue, chikungunya e febre pelo vírus da zika, até a Semana Epidemiológica (SE) 52 de 2017, foram registrados 28.162 casos prováveis e incidência de dengue por 100mil/hab.; em 2016, no mesmo período, esse número foi de 522.156 casos prováveis e incidência da dengue por 100mil/hab.

A Prefeitura de Governador Valadares apresentou, em de janeiro de 2017, o levantamento de Índice Rápido por Infestação de Aedes aegypti (LIRAa), que constatou $9,7 \%$ de imóveis com foco do mosquito na cidade. $O$ índice é superior ao último LIRAa de 2016 apresentado em novembro, quando foi registrado 7,9\% (GOVERNADOR VALADARES, 2017).

O bairro Santa Rita, localizado no município de Governador Valadares, segundo os dados do IBGE, em 2010 já possuia população estimada em 19.687 habitantes. O bairro é um dos mais populosos da cidade e sua população corresponde a 7,47\% da população total do município, segundo o IBGE 2010. Portanto, o objetivo deste trabalho foi analisar os casos de dengue no referido bairro no período de 2016 e 2017, assim como realizar uma comparação entre os anos e verificar a oscilação de casos de um ano para o outro. A relevância da pesquisa está no fato de a dengue ser uma doença com grande recorrência, o que a torna assunto merecedor de atenção e acompanhamento. 


\section{MATERIAL E MÉTODOS}

O presente trabalho foi embasado em pesquisa de análise quantitativa indireta, que compreendeu a análise do total de notificações/investigações dos casos de dengue no bairro Santa Rita, no município de Governador Valadares/MG, bairro que apresenta alta densidade populacional em relação às demais regiões.

Para a pesquisa, inicialmente, buscou-se os dados da incidência de doença no referido bairro, de janeiro de 2016 a dezembro de 2017, junto à Gerência de Epidemiologia do município supracitado. Esses dados foram fornecidos pela Gerência por meio do preenchimento da ficha de notificação do Sistema de Informação de Agravo de Notificação (SINAN).

Logo após, a totalidade dos casos notificados foi descrito em quatro grupos, a saber: dengue clássica, dengue com complicação, descartados (negativo para a dengue) e inconclusivos (falta de dados ou divergência entre a ficha de notificações e o rótulo da amostra). Em seguida, realizou-se pesquisa no site do IBGE para precisar a população de Governador Valadares.

A partir dos números de infectados naquele bairro, construiu-se um gráfico, o qual apresentou o total de casos notificados, por grupo e por ano, e também o total dessas notificações, por grupo, no biênio. Por fim, foi calculada a porcentagem do número de infectados em relação ao total da população do município, com base nos dados do IBGE.

\section{RESULTADOS E DISCUSSÃO}

O controle da dengue nos municípios se tornou uma tarefa complexa, sendo que a prevenção baseada no controle do vetor se mostra como a forma mais eficaz devido à inexistência de vacina (DE OLIVEIRA et al., 2016). Para auxiliar os municípios no combate à dengue, o Governo Federal propicia ferramentas que auxiliam nessa tarefa, como o mapeamento da doença pelo LIRAa. Dessa forma o município tem maior controle sobre os casos apresentados (SANTOS; SILVA, 2015).

De acordo com os dados coletados, o bairro Santa Rita apresentado no total registrado nos dois anos foi de 487 notificações, sendo 265 casos de dengue clássico, (54,41\%), descartados 219 (44,97\%), 3 casos foram inconclusivos $(0,62 \%)$, não havendo notificações de dengue com complicações no período analisado, dados relacionados na tabela 1 .

TABELA 1 - Frequência por ano de notificação de dengue nos anos de 2016 e 2017 segundo classificação do SISNAN.

\begin{tabular}{|l|c|c|c|}
\hline Classificação & $\mathbf{2 0 1 6}$ & $\mathbf{2 0 1 7}$ & Total \\
\hline Dengue Clássico & 81 & 184 & 265 \\
\hline $\begin{array}{l}\text { Dengue com } \\
\text { complicações }\end{array}$ & 0 & 0 & 0 \\
\hline Descartado & 140 & 79 & 219 \\
\hline Inconclusivo & 3 & 0 & 3 \\
\hline Total & $\mathbf{2 2 4}$ & $\mathbf{2 6 3}$ & $\mathbf{4 8 7}$ \\
\hline
\end{tabular}

Fonte: Gerência de Epidemiologia de Governador Valadares, ano 2018.

$\mathrm{O}$ ano de 2016 teve um registro de 224 casos notificados de dengue: desses, 81 apresentaram dengue clássica, que representa $36,16 \%$ do total de casos do ano; $140(62,5 \%)$ foram descartados; $3(1,34 \%)$ inconclusivos; e não houve notificações de casos de dengue com complicações como pode ser visualizado no Gráfico 1. ENCICLOPÉDIA BIOSFERA, Centro Científico Conhecer - Goiânia, v.15 n.28; p.1244 
Nesse ano, a população estimada de Governador Valadares era de 279.665 habitantes, segundo o IBGE; dessa forma, o índice de infestação da doença no bairro corresponde a aproximadamente $0,029 \%$ do total da população estimada.

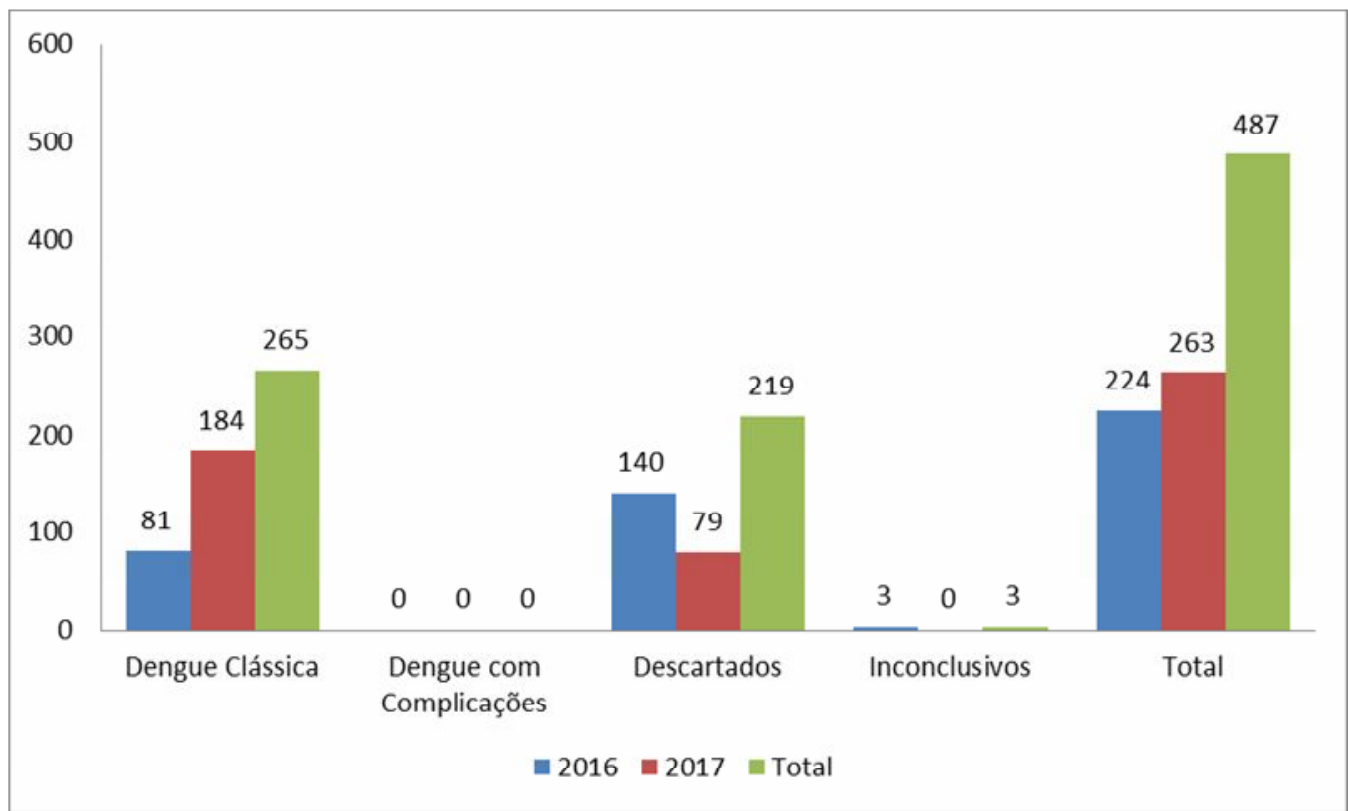

GRÁFICO 1 - Casos de dengue no bairro Santa Rita, Governador Valadares/MG nos ano de 2016 e 2017.

Fonte: Governador Valadares, 2018.

Já em 2017, foram registradas 263 notificações da doença: destas, 184 $(69,96 \%)$ apresentaram dengue clássica; 79 (30,04\%) descartados; não houve caso inconclusivo nem dengue com complicações (gráfico 1). Neste ano, a população estimada da cidade, segundo o IBGE, foi de 280.901 habitantes, e a população infectada do bairro correspondeu a aproximadamente $0,0655 \%$ da população da cidade. Constata-se um aumento de 17,41\% no registro de notificações em 2017 com relação a 2016.

No período de estudo, observou-se aumento tanto nas notificações $(17,41 \%)$ quanto nos casos comprovados de dengue clássica de $225,8 \%$. Conforme dados obtidos junto à Prefeitura do município, o levantamento do LIRAa constatou aumento no número de focos do mosquito na cidade, fato esse que pode se relacionar com o aumento do número de casos comprovados da doença na população do bairro.

Similar ao observado por Alecrim et al. (2016) no município de Ipatinga, constatou-se no bairro Santa Rita alto índice de dengue clássica que não representa a forma mais grave da doença, mas pode causar sintomas como mal- estar, febre, dor no corpo, afastando os indivíduos de suas atividades (gráfico 1). Ações estratégicas são fulcrais para o controle da doença e devem ser detalhadamente elaboradas de acordo com a realidade do município, a fim de que sejam eficazes no controle dos casos da doença.

O combate à dengue apresenta ações para a eliminação dos criadouros, limitadas e direcionadas para que a população atue de forma pontual, desconsiderando o controle de forma mais contextualizada, como deveriam ser as intervenções de educação em saúde. Observa-se que os programas de controle da dengue, na maioria das vezes, são voltados para repassar informações sobre os criadouros, como evitar e eliminá-los; logo, não estão focados em fornecer 
informações, a fim de a comunidade problematizar a situação em seu território (SANTOS; SILVA, 2015).

A participação da população no combate ao mosquito é fundamental para reduzir o número de casos. Sendo assim, intervenções educativas na população, que visem implantar conceitos, com discussões acerca do combate a doença, são indispensáveis à construção de uma mudança de padrões e hábitos em relação à dengue (PINTO et al., 2013).

Outro fator que contribui para o aumento do número de casos da doença é o desenvolvimento urbano, como ocorre no bairro em estudo. O agrupamento de indivíduos, a precariedade no saneamento básico, as moradias inadequadas são fatores educacionais e culturais que favorecem a proliferação do mosquito vetor da dengue. No bairro em estudo, pode-se observar ruas com saneamento básico precário, apresentando drenagem urbana insuficiente, resíduos sólidos expostos, sem o destino adequado.

A infraestrutura precária de saneamento básico, o acúmulo de lixo e entulho oportunizam a formação de novos criadouros no intra e peridomicílio. Portanto, as situações apresentadas no bairro propiciam aumento da proliferação do vetor e, consequentemente, aumento na transmissão da dengue. Medidas como mutirões de limpeza, força-tarefa e ações de retiradas de pneus nos estratos da cidade são ações de monitoramento de potencial positivo, considerando que esses são fatores que interferem para a reprodução do vetor (SOUZA, 2017).

Ressalta-se que as residências são os locais em que há mais focos do Aedes aegypti, deixando clara a importância de um trabalho conjunto de moradores com entidades governamentais responsáveis para a eliminação do mosquito transmissor da dengue (DIAS, 2010).

A Gestão Ambiental e a Saúde Pública estão intimamente ligadas quando se observa que as duas visam propiciar ao homem qualidade de vida, bem-estar e sobrevivência saudável no futuro, uma vez que objetiva o desenvolvimento sustentável. As preocupações com a problemática ambiental estão inseridas na Saúde Pública desde sua origem, embora apenas a partir de 1950 tenha se estruturado uma área exclusiva para tratar dessas questões(RIBEIRO et al., 2004). A Organização Mundial de Saúde (OMS) define saneamento como "controle de todos os fatores do meio físico do homem, que exercem ou podem exercer efeitos nocivos sobre seu bem-estar físico, mental e social" (RIBEIRO et al., 2004). O saneamento desempenha importante tarefa, dentro das Ciências Ambientais, e o investimento na qualidade do saneamento ajuda na prevenção de diversas doenças.

A educação ambiental voltada para a população pode ser considerada elemento essencial no controle do vetor. Nesse sentido, as campanhas públicas de prevenção constituem um componente importante na proposta de controle da doença, tanto no esclarecimento à população a respeito do trabalho dos órgãos de saúde quanto na ênfase à participação popular e atuação governamental (CESARINO et al., 2014).

A Sociedade Brasileira de Imunização enfatiza, por meio de um documento da Organização Mundial das Nações (OMS), que ações de contenção do vírus devem ter auxílio do esclarecimento populacional acerca da doença, um trabalho de vigilância epidemiológica estruturada, bem como um suporte hospitalar eficiente aos doentes, além de inserir vacinação em países com alto índice de infestação. Dessa forma, seria possível reduzir em até $30 \%$ o aparecimento de sintomas e hospitalização de contaminados pelo vírus (WHO, 2016). 


\section{CONCLUSÕES}

A dengue representa nos dias atuais um desafio premente tanto para os órgãos de saúde e de vigilância sanitária quanto para a sociedade. O aumento das notificações e casos de dengue que ocorreu no ano de 2017 para 2016, no bairro Santa Rita, em Governador Valadares, é alarmante e, por isso, deve ser analisado, enfocando-se em ações de monitoramento e contrição dos focos.

Trabalhos de sensibilização focados no bairro em estudo, bem como a promoção da educação ambiental e investimentos em saneamento, efetivados pelo Poder Público, são sugestões práticas para que aconteça a redução de locais propícios ao desenvolvimento do vetor. Vale salientar que a extensão territorial do município é considerável; por isso, o ideal é que tais práticas se expandam para outros bairros.

Além do mais, fatores ambientais estão intimamente ligados ao processo de controle do vetor. Dessa forma, a disposição correta dos resíduos sólidos em uma cidade, bairro e nas casas é uma das formas mais eficazes de combate à proliferação do mosquito.

Também é grande importância que estudos sejam realizados sobre o tema para que se busque a melhor solução no controle da doença, de modo a estabelecer uma qualidade de vida mais saudável para a população. Por fim, é relevante que a sociedade faça sua parte e se perceba como integrante do meio ambiente, transformando informação em atividade cotidiana e hábitos de monitoramento e combate ao foco dos vetores.

\section{REFERÊNCIAS}

ALECRIM, J. S.; COTTA, A.; CASTRO, J. M. Relação entre as ações de prevenção da dengue e o impacto causado sobre os casos notificados no município de Ipatinga entre os anos de 2009 e 2010290 Journal of Health Sciences, 2016; 18 (3): 286-0. Disponível

em:

http://www.pgsskroton.com.br/seer/index.php/JHealthSci/article/view/3834 Acesso em: 24 julho de 2018. ISS2447-8938 DOI: http://dx.doi.org/10.17921/24478938.2016v18n4p286-90

BONITA, R.; BEAGLEHOLE, R. Epidemiologia básica. São Paulo: Santos, 2010.

BRASIL. Ministério da Saúde. Portaria №1271: Define a Lista Nacional de Notificação Compulsória de doenças, agravos e eventos de saúde pública nos serviços de saúde públicos e privados em todo o território nacional, nos termos do anexo, e dá outras providências. Disponível em: <bvsms.saude.gov.br/ saudelegis/gm/2014/prt1271_06_06_2014.html>. Acesso em: 10 nov. 2017.

BRASIL. Ministério da Saúde. Secretaria de Vigilância em Saúde. Guia de Vigilância em Saúde. Brasília: Ministério da Saúde, 2014.

BRASIL. Ministério da Saúde. Secretaria de Vigilância em Saúde. Monitoramento dos casos de dengue, febre de chikungunya e febre pelo vírus Zika até a Semana Epidemiológica 50, 2017. Boletim Epidemiológico, v. 49, n. 2, 1-13, 2018. Disponível em: <http://portalarquivos2.saude.gov.br/images/pdf/2018/janeiro/23/Boletim-2018-001Dengue.pdf > Acesso em: 29 junho 2018. 
BRAGA, I. A.; VALLE, D. Aedes aegypti: histórico do controle no Brasil. Epidemiologia e Serviços de Saúde, Brasília, v. 16, n. 2, p. 113-118, jun. 2007. Disponível em: <http://scielo.iec.gov.br/scielo.php?script=sci_arttext\&pid=S167949742007000200006\&lng=pt\&nrm=iso >. Acesso em: 11 nov. 2017. ISSN0103-4014

CAMARA, Fernando Portela et al. Estudo retrospectivo (histórico) da dengue no Brasil: características regionais e dinâmicas. Revista da Sociedade Brasileira de Medicina Tropical, Uberaba, v. 40, n. 2, p. 192-196, Apr. 2007 . Available from $<$ http://www.scielo.br/scielo.php?script=sci_arttext\&pid=S0037-

86822007000200009\&lng=en\&nrm=iso >. access on 20 jul. 2018. http://dx.doi.org/10.1590/S0037-86822007000200009.

CATÃO, C. R. Dengue no Brasil: abordagem geográfica na escala nacional. São Paulo: Cultura Acadêmica, 2012.

CESARINO, M. B. et al. A difícil interface controle de vetores atenção básica: inserção dos agentes de controle de vetores da dengue junto às equipes de saúde das unidades básicas no município de São José do Rio Preto, SP. Saúde e Sociedade, 2014;23(3):1018-32. ISSN 0104-1290

COSTA, F .S. et al . Dinâmica populacional de Aedes aegypti (L) em área urbana de alta incidência de dengue. Revista da Sociedade Brasileira de Medicina Tropical, Uberaba , v. 41, n. 3, p. 309-312, June 2008 . Available from $<$ http://www.scielo.br/scielo.php?script=sci_arttext\&pid=S0037$86822008000300018 \& \mathrm{lng}=\mathrm{en} \& \mathrm{nrm}=\mathrm{iso}>$. access on 20 Sept. 2018. http://dx.doi.org/10.1590/S0037-86822008000300018.

DE OLIVEIRA, F. L. B. et al. Dengue: prevenção e controle pelas ondas do rádio. Revista Extensão e Sociedade, 2016; 5(2):47-52. ISSN 21786054

DIAS, L. B. A. et al. Dengue: transmissão, aspectos clínicos, diagnóstico e tratamento. Medicina (Ribeirão Preto), v. 43, n.2, p.143-52, 2010. Disponível em: <http://www.revistas.usp.br/rmrp/article/view/171/172>. Acesso em: 21 mar. 2018. DOI: https://doi.org/10.11606/issn.2176-7262.v43i2p143-152

FERREIRA, A. C.; CHIAVARALLOTI-NETO, F.; MONDINI, A. Epidemiologia espacial da dengue em Araraquara, São Paulo, Brasil. Investigação 2016;15(6). Disponível em http://publicacoes.unifran.br/index.php/investigacao/article/ view/1616 DOI: http://dx.doi.org/10.26843/investigacao.v15i6.1616

GOVERNADOR VALADARES. Prefeitura. Dengue: $1^{\circ}$ LIRAade 2017 aponta aumento no número de focos do mosquito. Disponível em: <http://www.valadares.mg.gov.br/detalhe da-matéria/info/dengue-10-liraa-de-2017aponta-aumento-no-numero-de-focos-do-mosquito/53160>. Acesso em : 25 nov.2017.

GUZMAN, M. G. et al. Dengue: a continuing global threat. Nature Reviews Microbiology, 2010; 7-16 doi: 10.1038/nrmicro2460. 
INSTITUTO OSWALDO CRUZ. Dengue, vírus e vetor: 10 minutos contra o Aedes. Disponível em: <http://www.ioc.fiocruz.br/dengue/textos/10minutos.html.>. Acesso em: 31 out. 2017.

IBGE. Censo 2010. Disponível em:<www.ibge.gov.br.> Acesso em: 27 out. 2017.

JACOBI, P. R.; BESEN, G. R. Gestão de resíduos sólidos em São Paulo: desafios da sustentabilidade. Estudos avançados, São Paulo, v. 25, n. 71, abr. 2011. Disponível em: <http://www.scielo.br/scielo.php?pid=S010340142011000100010\&script=sci_arttextt>. Acesso em: 5 maio 2016. http://dx.doi.org/10.1590/S0103-40142011000100010

LOPES, N.; NOZAWA, C.; LINHARES, R. E. C. Características gerais e epidemiologia dos arbovírus emergentes no Brasil. Revista Pan-Amazônica de Saúde v.5 n.3 Ananindeua set. 2014 versão On-line ISSN 2176-6223 http://scielo.iec.gov.br/scielo.php?script=sci_arttext\&pid=S217662232014000300007 Acesso em 25 julho 2018 doi: 10.5123/S217662232014000300007

MINAS GERAIS. Secretaria de Estado de Saúde. Ações de mobilização contra o Aedes aegypti aumentam $113 \%$ em Minas Gerais. 2017. Disponível em: $<$ www.saude.mg.gov.br/component/gmg/story/9454-acoes-de-mobilizacao-contra-oaedes-aegypti-aumentam-113-em-minas-gerais>. Acesso em: 31 nov. 2017.

PESSOA, J.; OLIVEIRA, E.; LEMOS, C. S.; TEIXEIRA, R. Implantação da política de integração entre Agentes de Combate de Endemias e Agente Comunitário de Saúde no controle da dengue. Goiânia, Goiás, Brasil. In: CONGRESSO IBEROAMERICANO EM INVESTIGAÇÃO QUALITATIVA, 4., Aracaju. Proceeding, 2015. Disponível em: <https://proceedings.ciaiq.org/index.php/ciaiq2015/article/view/109/105>. Acesso em: 23 maio 2018. DOI: 10.1590/1413-81232015218.05462016

PINTO, P. S.; PINTO, F. O.; DUARTE, S. C. A Dengue e sua relação com Educação Ambiental no município de Quissamã/RJ. Revista Científica da Faculdade de Medicina de Campos - Volume 8 - Número 1 - Maio de 2013 ISSN 1980-7813

PONTES, R. J. S.; RUFFINO-NETTO, A. Dengue em localidade urbana da região sudeste do Brasil: aspectos epidemiológicos. Revista Saúde Pública, 28: 218-27, 1994 ISSN 1518-8787.

RODRIGUES, W.; MAGALHÃES FILHO, L. N. L., PEREIRA, R. D. S. Análise dos Determinantes dos custos de resíduos sólidos urbanos nas capitais estaduais brasileiras. Urbe. Revista Brasileira de Gestão Urbana. 2016; 8(1):130141.ISSN21753369.

RIBEIRO, H. Saúde Pública e meio ambiente: evolução do conhecimento e da prática, alguns aspectos éticos. Saúde e sociedade, São Paulo, v. 13, n. 1, p. 7080, Apr. 2004 Available from $<$ http://www.scielo.br/scielo.php?script=sci_arttext\&pid=S0104- 
$12902004000100008 \&$ Ing=en\&nrm=iso $>$ access on 18 JUL. 2018. http://dx.doi.org/10.1590/S0104-12902004000100008.

>. Acesso em: 18 JUL. 2018.

SANTOS, I.M.; SILVA, S. S. Avaliação das ações de controle da dengue em Itabuna/BA sob a ótica da população. Revista Polyphonía, 2015; 26(1): 275-82. ISSN 2238-8850 Disponível

em: <https://www.revistas.ufg.br/sv/article/view/38030/19119

SOUZA, J. P; SOUZA, C. D. F.; FERREIRA, J. M. S; HERRERA, K. M. S. Ações interativas no combate a dengue e chikungunya em Divinópolis/MG, Brasil. Revista Ciência em Extensão, [S.I.], v. 13, n. 4, p. 10-19, dez. 2017. ISSN 16794605. Disponível em: <http://ojs.unesp.br/index.php/revista_proex/article/view/1705>. Acesso em: 18 set. 2018.

WHO. Dengue vaccine: WHO position paper - July 2016. Weekly Epidemiological Record, n. 30, 29 July 2016. Disponível em: <https://sbim.org.br/noticias/556-omsrecomenda-vacinacao-publica-contra-a-dengue-em-paises-com-alto-numero-decasos-da-doencas>. Acesso em: 20 abr. 2018. 